\title{
Tree Growth Variability of Pinus heldreichii at Tree-Line Locations in Kosovo**
}

\author{
Faruk Bojaxhi ${ }^{1, *}$, Ervin Toromani ${ }^{2}$, Nehat Çollaku ${ }^{2}$
}

(1) University of Prizren, Forestry and Environment Faculty, Rruga e Shkronjave, nr.1, Prizren, Kosovo**; (2) Agricutural University of Tirana, Faculty of Forestry Sciences, Koder Kamez, AL-1029 Tirana, Albania

* Correspondence: e-mail: farukbojaxhi@yahoo.com

** This designation is without prejudice to position on status, and is in line with UNSC 1244 and the ICJ Opinion on the Kosovo declaration of independence.
Citation: Bojaxhi F, Toromani E, Çollaku N, 2020. Tree Growth Variability of Pinus heldreichii at Tree-Line Locations in Kosovo. South-east Eur for 11(2): early view. https://doi.org/10.15177/ seefor.20-11.

Received: 7 Mar 2020; Revised: 14 Jun 2020; Accepted: 19 Jun 2020; Published online: 21 Sep 2020

\begin{abstract}
It is well-known that tree growth at the upper treeline is controlled by low temperatures and limited seasonal growth. The study's objective was to investigate the climate warming effects on Bosnian pine (BP; Pinus heldreichii Christ.) growth during the $20^{\text {th }}$ century. We hypothesized that, like all the other drought-stressed conifers growing on tree-line locations, $\mathrm{BP}$ responds significantly to climate factors that control their growth. Three natural forest stands of BP were selected in Prevalla, Decan and Koritnik. The cores were taken from 98 dominant and co-dominant BP trees at breast height with no sign of human interference. The tree-ring widths were measured at $0.001 \mathrm{~mm}$ precision, with a LINTAB 6 (RINNTECH, Heidelberg) system and TSAP-Win Scientific software. A set of three BP tree-ring width chronologies were developed by trees spread on a typical mountain slope at elevations ranging from 1815 to $1945 \mathrm{~m}$ above sea level. The tree-ring chronologies from three sites showed significant correlation and this agreement decreased with the distance between sites. The length of the master chronologies varies among sites ranging from 176 years (Koritnik) to 541 years (Decani). The tree growth was controlled by a common climatic signal (local temperatures) and drought during midsummer across the investigated sites. These results confirm the assumption that tree growth at tree-line sites is controlled by low temperatures and drought conditions during the midsummer.
\end{abstract}

Keywords: Bosnian pine; tree line, SPEI; Forward Evolutionary Interval Analysis

\section{INTRODUCTION}

Bosnian pine (Pinus heldreichii Christ., Hereafter "BP") is one of the main conifer species growing in Kosovo. The species inhabits high elevations (over 1500 ma.s.l) within the Western, South and South-Western Kosovo (Figure 1). Despite its limited distribution in the Balkans and southern Italy, the species has been widely used in dendroclimatic studies. Previous studies have been conducted in Bulgaria (Panayatov et al. 2009, 2010), Greece (Branders 2007, Griggs et al. 2007), and Albania (Seim et al. 2012), exploring climate-growth relationship of this high-elevation species. Moreover, summer temperature was reconstructed (17682008), based on maximum latewood density measurements of $P$. heldreichii trees from a high-elevation stand in the Pirin Mountains in Bulgaria (Trouet et al. 2012). In Albania, a 1391year tree-ring width chronology (617-2008) was developed and maximum density measurements were acquired on living and dead $P$. heldreichii trees (Seim et al. 2010).

The overall forest area covered by P.heldreichii in Kosovo amounts to 2150 ha, mostly mixed with species like silver fir (Abies alba Mill.). Some natural forest stands of this species exist in Kosovo, situated in Prevalla, Koritnik and Decani regions respectively, but only two dendroclimatic studies have been conducted to date (Bojaxhi and Toromani 2016, 2017). The high conservational value of such taxa additionally increases the importance of tree-ring width-based studies that allow a better understanding of the climate - radial growth relationship as well as eco-physiological requirements of trees.

Previous dendroclimatic studies conducted in Kosovo found that BP growing in high elevation locations is sensitive to summer drought stress and the magnitude of sensitivity was higher in young trees. The negative effect of summer 
drought stress on BP radial growth is expected to be more pronounced with climate warming in the coming years.

In order to enhance our understanding of climate warming effects on BP growth during the $20^{\text {th }}$ century, we aimed to pursue this study following these objectives: (i) assessing the cross-dating potential of BP growing on various sites; (ii) investigating the potential relationships between climate and BP growth, and (iii) elucidate temporal and spatial variability in relationships identified between climate and BP. We hypothesized that, like the other droughtstressed conifers growing on tree-line locations, BP responds to climate factors that influence moisture availability. An improved perspective of the dendroclimatic potential of
BP could enhance our understanding of climate effects in natural ecosystems and strengthen the spatial and temporal resolution of the tree-ring record in Kosovo.

\section{MATERIALS AND METHODS}

\section{Study Sites}

The study area includes natural ecosystems located close to the upper distribution limit of BP at Prevalla (hereafter, PRE) - (42 ${ }^{\circ} 11^{\prime} \mathrm{N}, 20^{\circ} 57^{\prime} \mathrm{E} ; 1945 \mathrm{~m}$ a.s.I), Decan (hereafter DE) - $\left(42^{\circ} 36^{\prime} \mathrm{N}, 20^{\circ} 14^{\prime} \mathrm{E} ; 1830 \mathrm{~m}\right.$ a.s.I), and Koritnik (hereafter, KO) - $\left(42^{\circ} 04^{\prime} \mathrm{N}, 20^{\circ} 31^{\prime} \mathrm{E} ; 1815 \mathrm{~m}\right.$ a.s.l) in western and southern Kosovo (Table 1, Figure 1).

Table 1. Site characteristics of the sampled sites.

\begin{tabular}{|c|c|c|c|c|c|}
\hline Sampled site & Latitude/ longitude & $\begin{array}{l}\text { Altitude } \\
\text { (m a.s.I.) }\end{array}$ & Aspect & Soil/rock formation & Sampled trees \\
\hline $\begin{array}{l}\text { Prevalle } \\
\text { (PRE) }\end{array}$ & $\begin{array}{l}\text { N } 42^{\circ} 111^{\prime} 01.3^{\prime \prime} \\
\text { E } 20^{\circ} 57^{\prime} 42.0^{\prime \prime}\end{array}$ & 1945 & SW & $\begin{array}{c}\text { Typical rendzina soils on limestone } \\
\text { bedrock }\end{array}$ & 30 \\
\hline $\begin{array}{l}\text { Decan } \\
\text { (DE) }\end{array}$ & $\begin{array}{l}\text { N } 42^{\circ} 36^{\prime} 19.8^{\prime \prime} \\
\text { E } 20^{\circ} 14^{\prime} 52.5^{\prime \prime}\end{array}$ & 1830 & NW & Brown soils on limestone bedrock & 38 \\
\hline Koritnik (KO) & $\begin{array}{l}\text { N } 42^{\circ} 04^{\prime} 46.5^{\prime \prime} \\
\text { E } 20^{\circ} 31^{\prime} 58.6^{\prime \prime}\end{array}$ & 1815 & NW & $\begin{array}{l}\text { Grayish-brown rendzina soils on } \\
\text { limestone bedrock }\end{array}$ & 30 \\
\hline
\end{tabular}

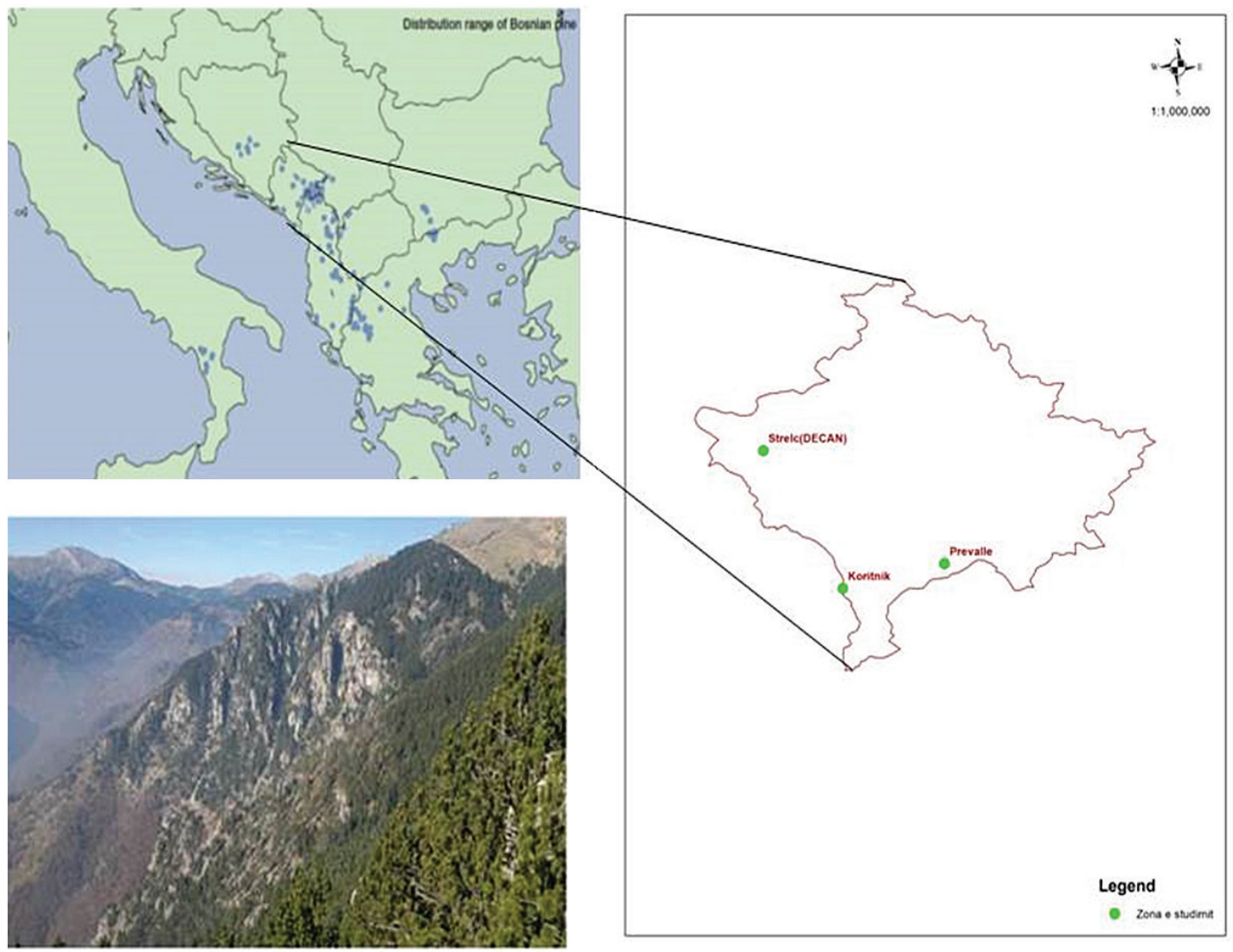

Figure 1. Distribution map of Bosnian pine (upper left side) in Europe and sampled sites from Kosovo (right side). 
Soil types formed on limestone bedrocks are dominated by leptosols (rendzinas) and brown soils and have slight differences among sites. At all sampled sites BP is the dominant species, while the ground vegetation comprises species such as Sesleria autumnalis Ard., Brachypodium sylvaticum Huds., Carex humilis Leyess., Thymus balcanus L., Fragaria vesca L., Festuca heterophylla Lam., Dactylus glomerata L., etc. These forest stands are growing under the effect of continental climate with some influences of the Mediterranean climate in southern Kosovo. The mean annual temperature varied among sampled sites and ranged from $8.0^{\circ} \mathrm{C}$ (PRE) to $8.3^{\circ} \mathrm{C}(\mathrm{KO})$. The average annual precipitation ranged from $791 \mathrm{~mm}$ (DE) to $1029 \mathrm{~mm}$ (KO) (CRU TS. v 3.22 dataset by Jones 2014, period 1901-2013) and is bimodally distributed with a pronounced maximum during May and a secondary peak in November (Figure 2). The growing season at all three sites lasts 5 months, from May to September. The natural forest stands of BP grow on sites with different slope aspects ranging from NW for $D E$ and KO sites to SW for PRE site.

\section{Field and Laboratory Methods}

The collection of samples took place from July to September 2014. In total, 89 trees were sampled, and two cores per tree were extracted at breast height (ca $1.3 \mathrm{~m}$ from ground) with an increment borer, but only 85 sampled trees were used to build chronologies at three sites. Dominant and co-dominant BP trees with umbrella-like crowns growing on shallow and poor soils were cored to obtain a sensitive chronology. Increment cores were dried fixed onto wooden mounts with cells vertically aligned (Stokes and Smiley 1996) and sanded. All cores were surfaced using progressively finer sandpaper beginning with ANSI 120-grit and finishing with ANSI 400-grit. Some cores could not be included in our dendroclimatological analyses due to ring anomalies associated with the lobate growth form, twisted stems, and predominance of false rings that mimicked true rings (Schweingruber 1993). Annual tree-ring widths were measured to an accuracy of $0.001 \mathrm{~mm}$ using a LINTAB 6 (RINNTECH, Heidelberg) system and TSAP-Win computer software. Cores were visually cross-dated and cross dating was statistically verified with COFECHA software (Holmes 1983). Each measured radius was processed by COFECHA as an individual time-series subdivided into 40-year segments sequentially overlapped by 20 years. We used the ARSTAN program (Cook 1985) to standardize all series applying a double detrending procedure to remove adverse growth effects from age-related growth trends, autocorrelation, and possible natural or anthropogenic influences that could interfere with the climate signal within the growth rings. First, detrending was conducted using a negative exponential curve and then second detrending was done by using cubic smoothing spline curves of 30 years in order to preserve the common climatic signal. The actual ring measurement was then divided by the predicted value to produce a dimensionless index of growth for that year (mean=1.0).A final master chronology was created for each site from the tree-ring data by averaging all indices of tree growth for each year across all series (Cook 1985). Chronology quality was estimated using $\mathrm{R}_{\mathrm{bar}}$ and Expressed Population Signal statistics (EPS) with a limit value of 0.85
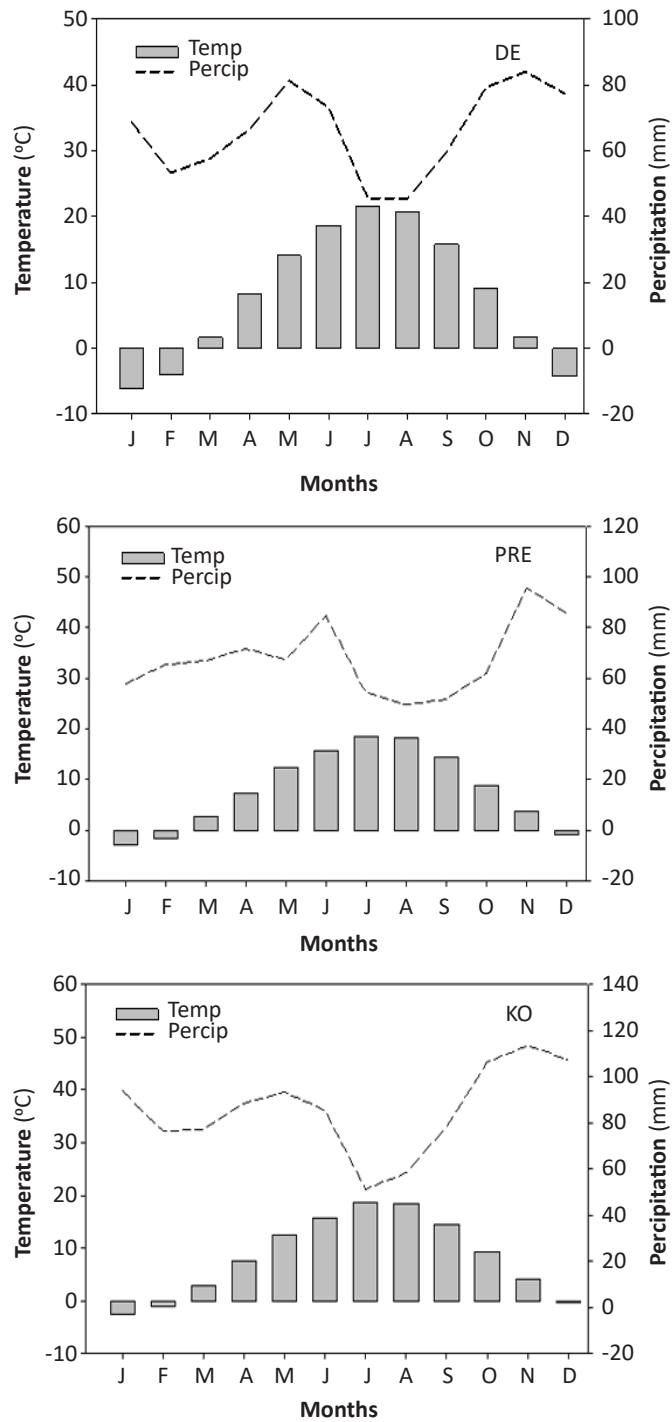

Figure 2. Climatic diagrams of the studied sites based on the CRU TS v3.22 data. Dashed line shows precipitation, while bars show temperature values.

(Wigley et al. 1984). $R_{b a r}$ is a measure of the strength of the common growth "signal" within the chronology (Briffa and Jones 1990), while the EPS is an estimate of the chronology's ability to represent the signal strength of a chronology on a theoretical infinite population (Briffa and Jones 1990). Three chronologies (standard, residual and arstan) were developed by the program ARSTAN, and we used the residual chronologies in our additional analyses.

\section{Climate-Growth Analyses}

The climate-growth relationship was assessed by means of bootstrap correlation analysis estimated by Dendro-Clim 2002 program (Biondi 1997, Biondi and Waikul 2004). Due to 
the lack of representative meteorological data for the whole period covered by our chronologies, we used datasets from the Climate Research Unit (CRU) for mean temperature and total precipitation. The chosen climate data were derived from the nearest points of the CRU grid with the sampled sites and were used in the climate-growth relationship. We also used the Standardised Precipitation-Evapotranspiration Index (SPEI) at 1- and 3-months'time scale in the period 1901-2013. The SPEI is a multiscale drought index based on the monthly precipitation and potential evapotranspiration from the CRU datasets (Vicente-Serrano et al. 2010).

Tree-ring chronologies were calibrated against instrumental climate records obtained from the CRUTS3.22 dataset (http://www.cru.uea.ac.uk/), for the period 19012013 with a spatial resolution of $0.5 \times 0.5^{\circ}$ (Mitchell and Jones 2005), using correlation and response functions analysis. Correlation analysis was performed to quantify the relationship between the residual chronologies from three sites and monthly mean temperature, total precipitation (Fritts 1976) and drought index (SPEI) for 1 and 3 months.

Correlation coefficients were deemed statistically significant at the $\mathrm{P}<0.05$ level, as shown by bootstrapped confidence intervals. The considered window for exploring the relations between climate and tree growth were from May of the prior year of growth to October of the current year of growth, assuming that the cambial activity of BP continues during the winter months and studying the role of climate during the previous year on the current radial growth (Fritts 1976, Grissino-Mayer 1995).

Then we applied forward evolutionary interval analysis (FEI) to provide a complementary assessment of temporal stability for significant monthly climate-growth relationships. Our objective was to elucidate temporal variability in the relationships identified between climate and BP radial growth (Biondi 1997, Biondi and Waikul 2004). FEl begins with the earliest year in common to all variables, from which forward evolutionary intervals are progressively enlarged by adding one year to a base interval length at each iteration (Biondi and Waikul 2004). Persistent relationships between climate variables and tree growth over the $20^{\text {th }}$ century would further substantiate the results of correlation analysis and suggest the suitability of BP tree-ring data for use in dendroclimatic reconstructions.

\section{RESULTS}

\section{Tree-Ring Chronologies}

The length of the master chronologies varies among sites. The DE chronology was the longest with 541 years, spanning the period $1474-2014$ with a replication of more than 34 trees from 1770 onwards. The KO chronology was the shortest, 176 years long, with a sample replication of 25 trees, while the PRE chronology was 243 years long, spanning the period $1776-2014$ with a samples replication of 25 trees from 1901 onwards (Figure 3, Table 2). The maximum value of inter-annual variability, expressed by the mean sensitivity (MS), was found in the KO, while the minimal value was found in the PRE chronology. High values
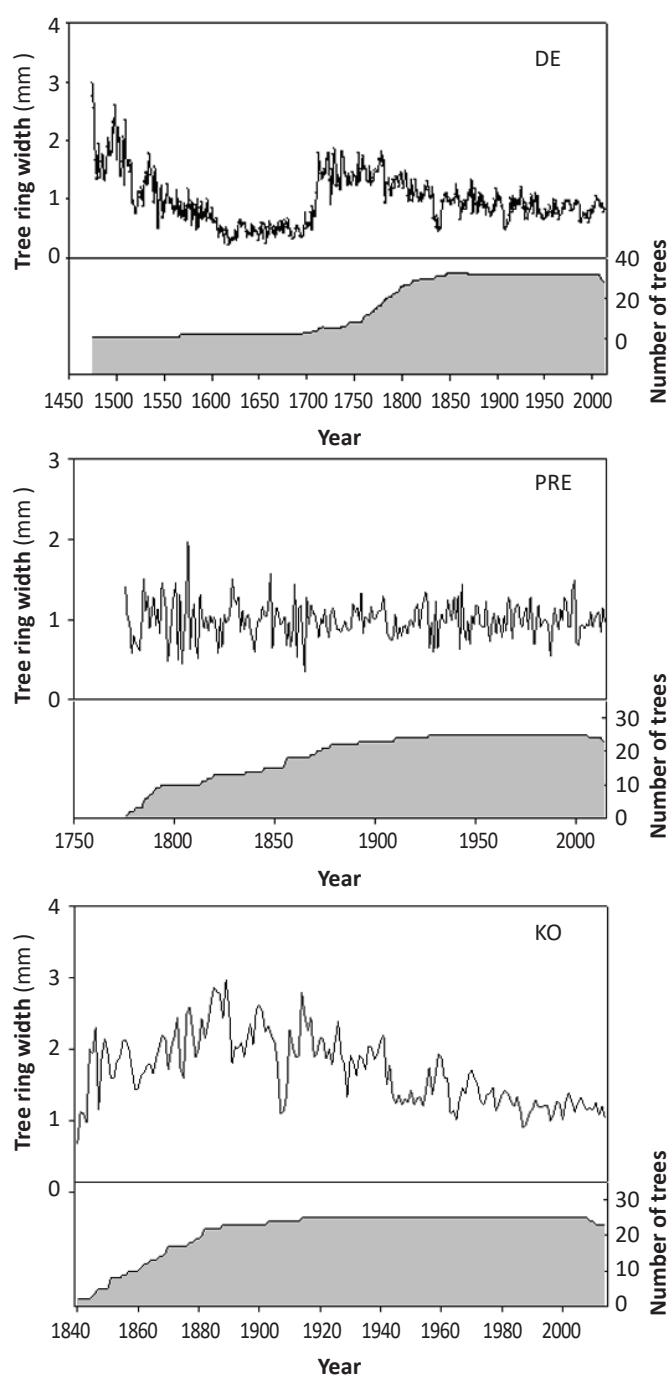

Figure 3. Tree-ring width chronologies of BP ( $P$. heldreichii Christ.) from Decan (DE), Prevalle (PRE) and Koritinik (KO). The upper part in each graph shows the raw tree-ring width chronology, while the lower part shows tree replication in respective site chronologies.

of the first-order autocorrelation found at all chronologies indicated that BP growth strongly depends on the climate conditions of the previous growing year.

All chronologies were significantly correlated with each other for the common period 1840-2014. The degree of agreement and similarity appears to be higher between $\mathrm{PRE}$ and KO chronology ( $\mathrm{R}=0.61 ; \mathrm{p}<0.01)$, but slightly lower among $D E$ and PRE chronologies ( $R=0.25 ; p<0.05)$, implying that the degree of correlation appears to be related to the vicinity between sites (Table 3). 


\section{Relationships Between Climate and Tree Growth}

The correlation between DE chronology and temperature was not significant at the study site, but significant relationships were found with October precipitation of the previous years of growth and summer months of the current growing year.

In addition, significant negative correlations were found between BP radial growth for KO site and monthly mean temperature for the previous July, August, September and current June. Moreover, BP radial growth in this site was negatively correlated with current May, but a positive correlation was found with previous August precipitation.

Bootstrapped correlation analysis between PRE chronology and climatic variables showed a positive relationship with current January - February temperatures, as well as with May and October precipitation of the previous years and July precipitation of the current growing year. An opposite relationship was found with previous June and current April precipitation (Figure 4).

The results of this analysis indicate that precipitation during the growing season is not the only limiting factor. Considering the number of significant coefficients of temperatures with a negative relation to growth, our analysis showed that this number was higher than those with a positive relation.

The results of the Pearson correlation between BP chronologies and SPEI in 1 to 3 months' time scales were different between sites (Figure 5). DE chronology had the highest positive correlation frequency with SPEI than the two other sites. These results indicate that young (PRE) and middle-aged (KO) trees are less sensitive to drought than old trees.

Thus, BP growth at DE site was positively correlated with SPEI values from June to August of the current year for 1 month time scale and from July to October of the current growing year for 3 months' time scale. Positive significant correlation between BP growth with July SPEI values was attained for two other sites. PRE chronology was the only one where 1 month time-scale SPEI was negatively correlated with BP growth and current April, implying that the low amount of rainfall during this month may delay the initiation of BP radial growth. Positive correlations found between SPEI and BP growth during July at all three sites show the impact of midsummer drought on trees' growth.

FEI suggested that these relationships were not all persistent during the period of inquiry. However, FEI indicated a sustained negative relationship between radial growth and current June monthly mean temperatures for PRE and KO sites, as well as a continuous positive relationship between growth and current January-February temperatures. FEI also indicated a persistent positive relationship between BP growth and previous May, July and August monthly precipitation at KO site and current June at DE site. Positive correlations found between SPEI and BP growth during July at all three sites show the impact of drought on trees' growth.

Table 2. Statistical parameters of three $P$. hedreichii chronologies from Kosovo.

\begin{tabular}{cccc}
\hline Statistical parameters & Decan (DE) & Koritnik (KO) & Prevalle (PRE) \\
\hline Time span & $1474-2014$ & $1840-2014$ & $1776-2014$ \\
Total years & 541 & 176 & 243 \\
Number of trees in chronology & 34 & 25 & 25 \\
Mean age (years) & $240 \pm 69$ & $147 \pm 18$ & $116 \pm 20$ \\
Mean tree-ring width (mm) & 1.06 & 1.81 & 2.13 \\
Standard deviation & 0.498 & 0.872 & 0.907 \\
Skewness & 1.037 & 0.995 & 0.547 \\
Mean Sensitivity (MS) & 0.224 & 0.245 & 0.212 \\
AC(1) & 0.769 & 0.751 & 0.783 \\
\hline
\end{tabular}

Table 3. Simple correlation coefficients of tree-ring chronologies between sampling sites. The asterisks indicate the significant values, $* p<0.05 ; * *<<0.01$.

\begin{tabular}{ccc}
\hline Site & Decan & Koritnik \\
\hline Decan & $0.35^{* *}$ & $0.25^{*}$ \\
Koritnik & & $0.61^{* *}$ \\
Prevalle & & \\
\hline
\end{tabular}




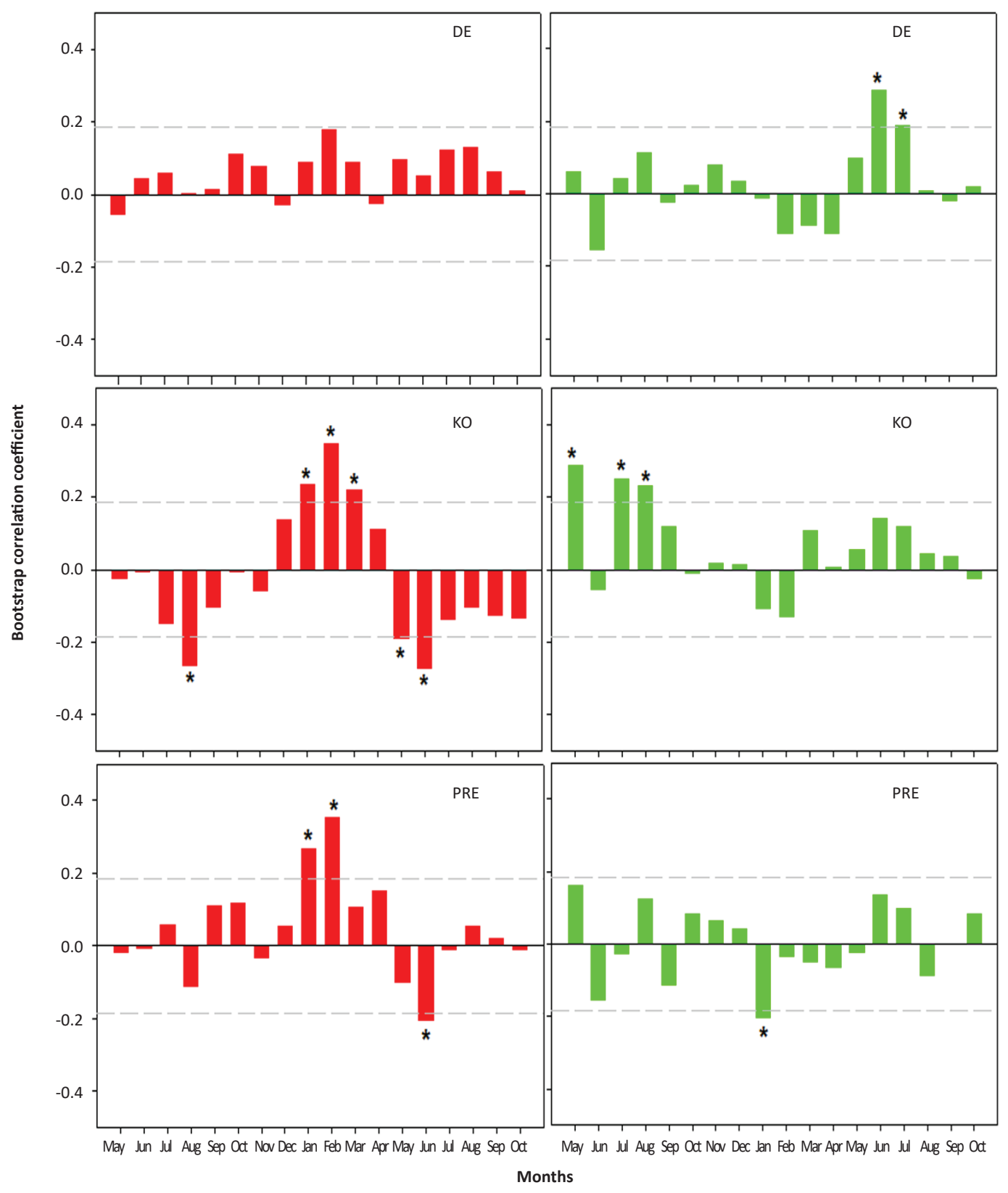

Figure 4. Bootstrap correlation coefficients between residual chronologies with temperature (left) and precipitation (right) from May of the year prior to growth to October of the current year of growth. Asterisks on the top of the bars indicate statistically significant correlations $(p<0.05)$ and the horizontal dashed lines represent the $95 \%$ confidence interval. 


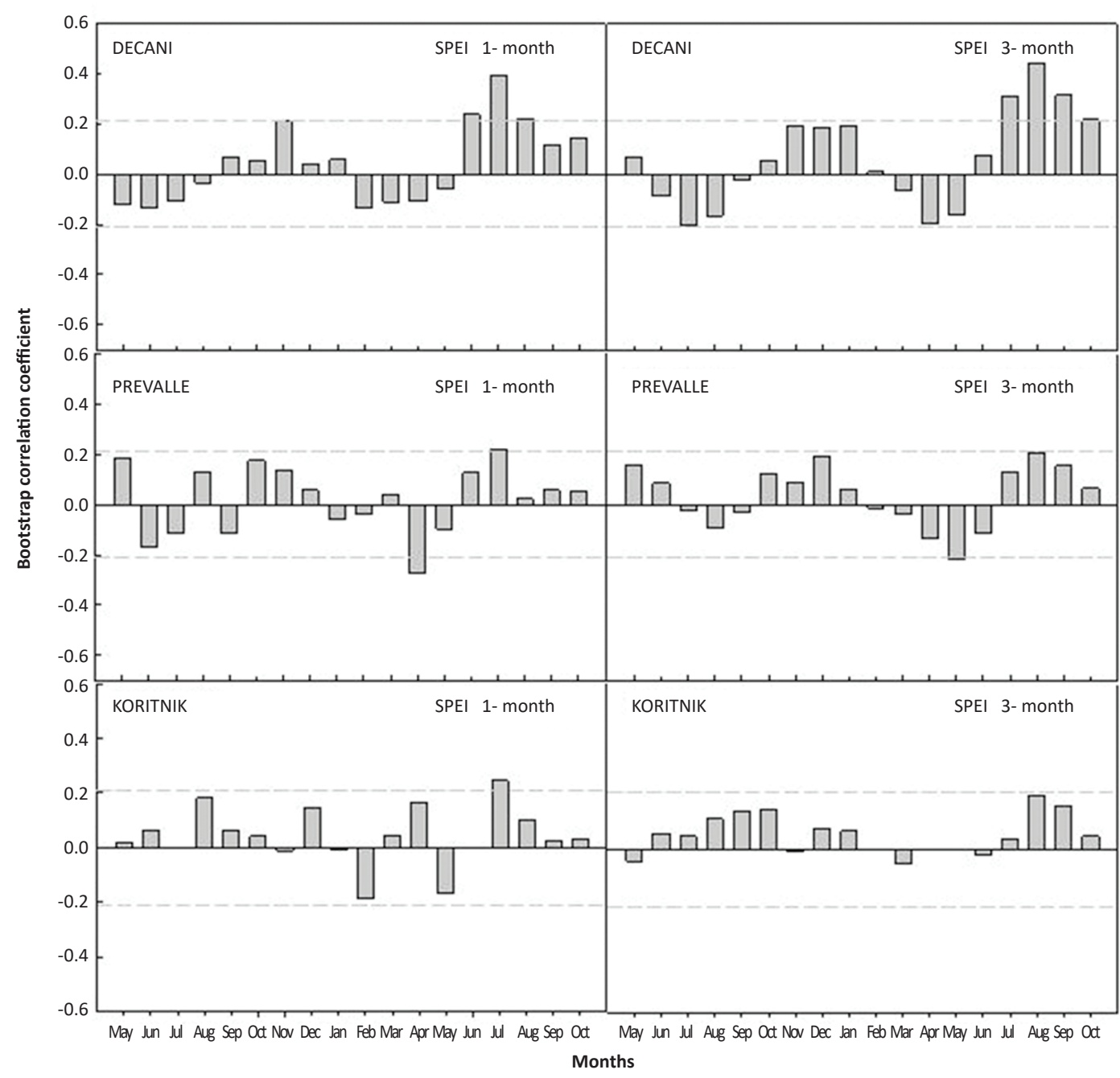

Figure 5. Correlation coefficients ( $y$-axis) showing the relationship between the BP residual chronology and monthly SPEI from the previous May to the current October for period 1951-2013. The horizontal dashed lines indicate the relationships between BP growth and SPEI values for a significance level of $p<0.05$. 


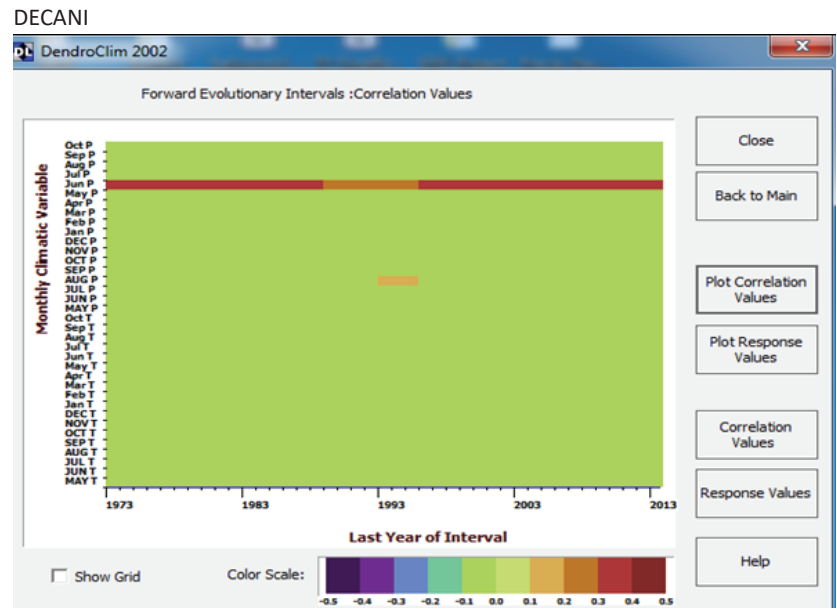

PREVALLE
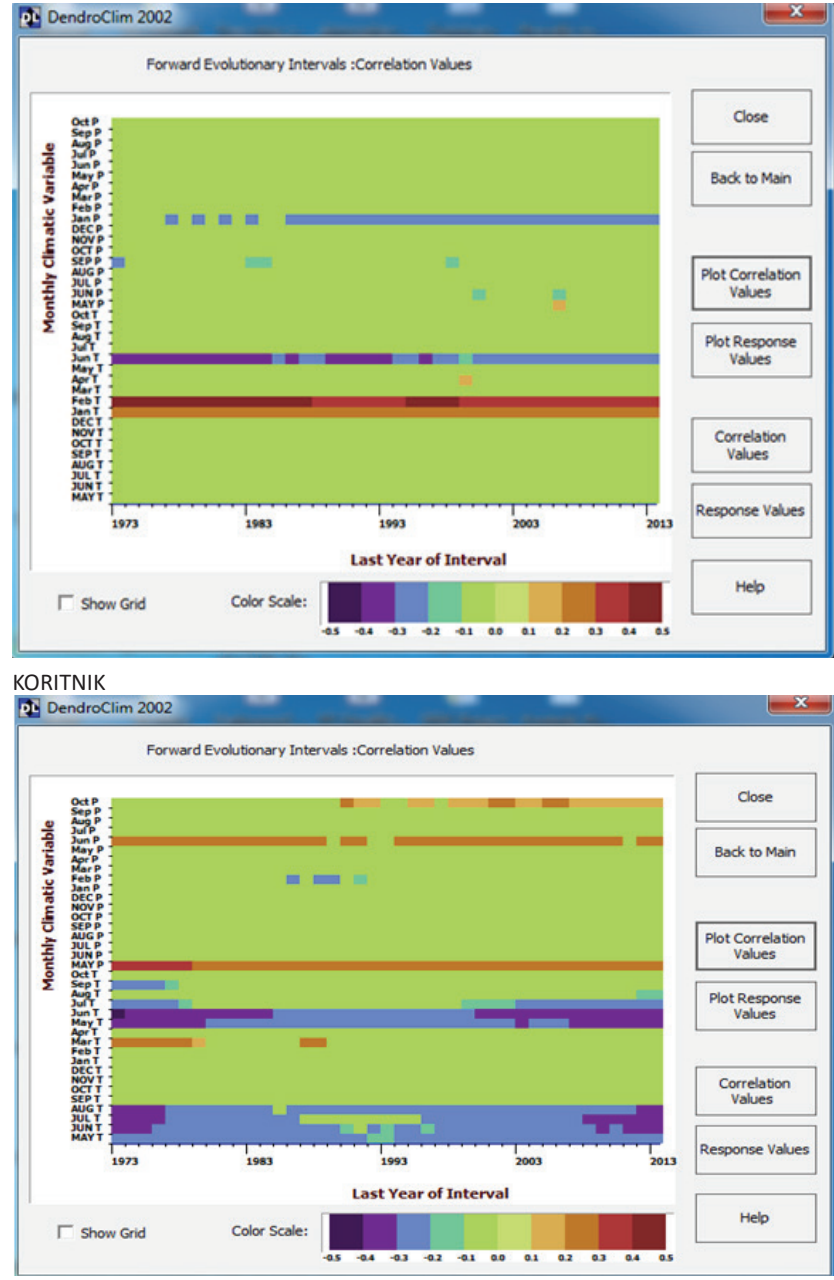

Figure 6. Results for forward evolutionary interval analysis (1951-2013) between monthly mean temperature and the BP chronology (32-year base interval). Monthly climatic variables are shown on the $y$-axis, beginning with the previous May and ending with the current October. The last years of the forward intervals are listed on the $x$-axis. Significant positive $(p<0.05)$ correlations are shown with colors ranging from brown to cherry, while significate negative $(p<0.05)$ correlations are shown with color from green to purple. 


\section{DISCUSSION AND CONCLUSION}

Radial growth trends shared between BP at the three sites indicate the influence of local climate conditions on species' growth. Significant correlations between BP chronologies and monthly climate data support our approach that BP growing on the studied sites is suitable for dendroclimatic analyses. A significant positive relationship between indexed BP growth and SPEI emerges during July in the current growing year. It suggests that the lack of precipitation during July is limiting the BP radial growth for the rest of the growing season. Thus, temperature rising and the lack of available water during July or summer months will lead to physiological dehydration and physiological drought in BP trees (Zhang et al. 2018). Drought stress will directly affect the transpiration and respiration of trees, leading to a reduction of the photosynthesis rate and eventually producing narrow tree-rings (Trugman et al. 2018). The severity of drought stress on individual trees closely depends on tree age. The drought in the study areas caused by temperature rising and lack of water availability, especially during July, has a strong limiting effect in trees of different age. In particular, the DE chronology composed by older trees, compared to other sites, showed more significant positive correlations with drought index (SPEI) than younger and middle-aged chronologies from PRE and $\mathrm{KO}$ sites. Older aged BP trees from DE site have bigger crown size, directly influencing the water balance through a higher evapotranspiration leading to a greater water consumption. This finding is consistent with the results of other studies indicating that age indirectly affects the trees' response to environmental factors due to photosynthesis efficiency, hydraulic conductance and nutrient transport (Vieira et al. 2009).

Jiao et al. (2017) reported that tree age could interfere with the expression of environmental signals related to radial growth and that the age effect is not completely eliminated from the developed chronologies. The KO site was the only one where1-month timescale SPEI (current April) was negatively correlated with BP growth, implying that the low amount of rainfall during this month may delay the initiation of BP radial growth. The decrease in available moisture during the beginning of the growing season could decrease the photosynthetic rate and cause trees to allocate fewer carbohydrates for radial growth (Fritts 1976, McDowell et al. 2008).

We found strong relationships between KO tree-ring chronology and temperatures of the year prior to the growth. In tree-line locations, the growing period is relatively short and most active tracheid's formation occurs at the beginning of the summer (Rossi et al. 2006). The inverse relationship between annual radial growth and monthly mean temperature during the previous late summer and early fall indicates that high monthly mean temperatures would increase evaporation rates and decrease the amount of water stored from summer rains. It is well-known that evaporation increases as monthly mean temperature increases, restricting the amount of water available for photosynthesis (Fritts 1976, McDowell et al. 2008). At PRE site a positive correlation with January and February temperatures was noted, implying that mild winters may have a positive influence on snow melting and soil moisture. From a physiological point of view, winter temperatures cannot directly influence cambial activity since the trees are dormant. However, during warmer winters, more precipitation falls as rainfall, rather than snow (IPCC 2007). In our case, it is more probable that precipitation in cases with warmer winter temperatures is in the form of wet snow, which on its side is less prone to wind transport and immediate sliding along steep slopes and therefore could contribute to a deeper snow cover. This can provide more soil moisture after snowmelt and could be a prerequisite for increased cambial activity given that other conditions are favorable.

Several possible explanations exist for the temporal instability of climate-growth relationships at the three sites. Climate is not the only environmental variable that affects the widths of tree-rings (Fritts 1976). It is possible that other non-climatic factors are responsible for erraticring patterns noted in all BP chronologies. Although there is no information about the anthropogenic activity, the presence of young trees especially in KO and PRE sites is a good indicator of silvicultural management treatments and this may partly explain the temporal variability in the relationships between radial growth and local climate. We noticed trunk scars and wounds on some trees at all three sites. These injuries were the result of lightening activity and might affect their growth. Therefore, biotic factors and anthropogenic activity, during the past and present, may partially explain the temporal instability of climate-growth relationships at all sampled sites.

It is projected that Kosovo will have increasingly warmer temperatures and a higher irregularity of precipitation in the future. Taking into account the role of drought during the summer season and temperatures on BP growth, their impact will likely become more important in the global warming scenarios.

\section{Author Contributions}

ET, FB carried out the field measurements, laboratory measurements and performed the statistical analysis, while SB and $\mathrm{BB}$ conducted the sample preparations. Both authors contributed to data collection and manuscript writing.

\section{Funding}

This research was conducted in the framework of the PhD thesis and no external funding has been used.

\section{Acknowledgments}

The authors would like to thank the reviewers for their valuable comments in manuscript improving.

\section{Conflict of Interest}

The authors declare no conflict of interest. 


\section{REFERENCES}

Biondi F, 1997. Evolutionary and moving response functions in dendroclimatology. Dendrochronologia 15: 139-150.

Biondi F, Waikul K, 2004. DENDROCLIM2002: A C++ program for statistical calibration of climate signals in tree-ring width chronologies. Comput Geosci 30(3): 303-311. https://doi. org/10.1016/i.cageo.2003.11.004.

Bojaxhi F, Toromani E, 2017. Spatial and Temporal Growth Variation of Pinus heldreichii Christ. Growing along a Latitudinal Gradient in Kosovo and Albania. South-east Eur for 8(2): 85-97. https:// doi.org/10.15177/seefor.17-10.

Bojaxhi F, Toromani E, 2016. The Growth of Bosnian Pine (Pinus heldreichii Christ.) at Tree Line Locations from Kosovo and its Response to Climate.South-east Eur for 7(2): 109-118. https:// doi.org/10.15177/seefor.16-10.

BrandersR, 2007.Waldgrenzen griechischer Hochgebirge: unter besonderer Berücksichtigung des Taygetos, Südpeloponnes. PhD thesis, Friedrich-Alexander University of Erlangen, Nurenberg, Germany, $259 \mathrm{p}$.

Briffa KR, Jones PD, 1990. Basic chronology statistics and assessment. In: Cook ER, Kairiukstis LA (eds) Methods of dendrochronology: applications in the environmental sciences. Springer Netherlands, pp 137-152. https://doi.org/10.1007/97894-015-7879-0.

Cook ER, 1985. A time series analysis approach to the tree-ring width standardization. Ph.D. Thesis, University of Arizona, Tucson, USA, $171 \mathrm{p}$.

Fritts HC, 1976. Tree Ring and Climate. Academic Press, New York, USA, $582 \mathrm{p}$.

Griggs C, DeGaetano A, Kuniholm P, Newton M, 2007. A regional high-frequency reconstruction of May-June precipitation in the north Aegean from oak tree rings, AD 1089-1989. Int J Climatol 27(8): 1075-1089. https://doi.org/10.1002/joc.1459.

Grissino-Mayer HD, 1995. Tree-Ring Reconstructions of Climate and Fire History at El Malpais National Monument, New Mexico. PhD Thesis, University of Arizona, Tucson, USA, $407 \mathrm{p}$.

Holmes RL, 1983. Computer-assisted quality control in tree-ring width dating and measurement. Tree-ring width Bull 43: 51-67.

IPCC, 2007. Climate Change 2007. The Physical Science Basis. In: Solomon S, Qin D, Manning M, Chen Z, Marquis M, Averyt KB, Tignor M, Miller HL (eds) Contribution of Working Group I to the Fourth Assessment Report of the IPCC. Cambridge University Press, Cambridge, UK, $996 \mathrm{p}$.

Jiao L, Jiang Y, Wang M, Zhang W, Zhang Y, 2017. Age-effect radial growth responses of Picea schrenkiana to climate change in the Eastern Tianshan Mountains, Northwest China. Forests 8: 294. https://doi.org/10.3390/f8090294.

McDowell N, Pockman WT, Allen CD, Breshears DD, Cobb N, Kolb T, Plaut J, Sperry J, West A, Williams DG, Yepez EA, 2008. Mechanisms of plant survival and mortality during drought: why do some plants survive while otherssuccumb to drought? New Phytol 178(4): 719-739. https://doi.org/10.1111/j.14698137.2008.02436.x.
Mitchell TD, Jones PD, 2005. An improved method of constructing a database of monthly climate observations and associated high-resolution grids. Int J Climatol 25(6): 693-712. https://doi. org/10.1002/joc.1181.

Panayotov M, Bebl P, Krumm F, Yurukov S, 2008. Tree rings in archaeology, climatology and ecology. Proceedings of the Dendrosymposium. Scientific Technical Report STR 09/03 7: 7176.

Panayatov M, Bebi P, Trouet V, Yurkov S, 2010. Climate signals in Pinus peuce and Pinus heldreichii tree-ring width chronologies from the Pirin Mountains in Bulgaria. Trees 24: 479-490. https:// doi.org/10.1007/s00468-010-0416-y.

Rossi S, Deslauriers A, Anfodillo T, Carrer M, 2008. Age-dependent xylogenesis in timberline conifers. New Phytol 177(1): 199-208. https://doi.org/10.1111/j.1469-8137.2007.02235.x.

Seim A, Buntgen U, Fonti P, Haska H, Herzig F, Tegel F, Trouet V, Treydte K, 2012. Climate sensitivity of a millennium-long pine chronology from Albania. Clim Res 51(3): 217-228. https://doi. org/10.3354/cr01076.

Seim A, Treydte K, Buntgen U, Esper J, Fonti P, Haska H, Herzig F, Tegel W, Faust D, 2010. Exploring the potential of Pinus heldreichii Christ. for long-term climate reconstruction in Albania, In: Levanic T, Gricar J, Hafner P, Krajnc R, Jagodic S, Gärtner H, Heinrich I, Helle G (eds) TRACE - Tree Rings in Archaeology, Climatology and Ecology, Vol. 8. GFZ Potsdam, Scientific Technical Report STR 10/05, Potsdam, Germany, pp. 75-82.Schweingruber FH, 1993. Trees and Wood in Dendrochronology. Springer Verlag, Berlin, Germany, 402 p. https://doi.org/10.1007/978-3-642-77157-6.

Stokes MA, Smiley TL, 1968. An introduction to tree ring dating. University of Chicago Press, Chicago, USA, $73 \mathrm{p}$.

Todaro L, Andreu L, D’alessandro CM, Gutierrez E, Cherubini $P$, Saracino A, 2007. Response of Pinus leucodermis to climate and anthropogenic activity in the National Park of Pollino (Basilicata, Southern Italy). Biol Conserv 137(4): 507-519. https://doi. org/10.1016/i.biocon.2007.03.010.

Trouet V, Panayotov M, Ivanova A, Frank D, 2012. A PanEuropean summer teleconnection mode recorded by a new temperature reconstruction from the eastern Mediterranean (1768-2008). Holocene 22(8): 887-898. https://doi. org/10.1177/0959683611434225.

Vicente-Serrano SM, Beguería S, López-Moreno JI, 2010. A Multiscalar drought index sensitive to global warming: the standardized precipitation evapotranspiration index - SPEI. J Clim 23(7): 1696-1718. https://doi.org/10.1175/2009JCLI2909.1.

Vieira J, Campelo F, Nabais C, 2009. Age-dependent responses of tree-ring growth and intra-annual density fluctuations of Pinus pinaster to Mediterranean climate. Trees 23: 257-265. https:// doi.org/10.1007/s00468-008-0273-0.

Wigley TML, Briffa KR, Jones PD, 1984. On the average value of correlated time series, with applications in dendroclimatology and hydrometeorology. J Climate Appl Meteorol 23(2): 201-213. https://doi.org/10.1175/1520-0450(1984)023<0201:OTAVOC>2 $.0 . \mathrm{CO} ; 2$. 